\title{
Globalização, Mobilidade e Trabalho na Rota do
}

\section{Turismo Popular ${ }^{1}$}

\author{
Globalización, Movilidad y Trabajo en la Ruta del \\ Turismo Popular
}

\author{
Globalization, Mobility and Work on the \\ Popular Tourism
}

\author{
Dra. Rosana Eduardo da Silva Leal ${ }^{2}$
}

\begin{abstract}
Resumo
O presente artigo buscará discutir as novas configurações do mundo do trabalho no âmbito da globalização, tendo como campo empírico o turismo popular proveniente das periferias do Recife. O objetivo é trazer à tona como os serviços turísticos populares inserem-se nos fluxos globais não-hegemônicos, promovendo o deslocamento e a sobrevivência de trabalhadores informais numa economia popular transnacional. Para a construção do trabalho, foram utilizados como ferramentas metodológicas os conteúdos teóricos, jornalísticos e empíricos, tendo como base a pesquisa etnográfica. A intenção é discutir antropologicamente como o turismo popular está contido na globalização não-hegemônica, na medida em que se apresenta como mercado de trabalho e ferramenta de mobilidade dos fatores de produção transnacionais, no âmbito da informalidade.
\end{abstract}

Palavras-chave: Globalização não-hegemônica, mobilidade, turismo popular, trabalho.

\section{Resumen}

El presente artículo buscará discutir las nuevas configuraciones del mundo del trabajo en el ámbito de la globalización, teniendo como campo empírico el turismo popular proveniente de las periferias del Recife. El objetivo es traer a la superficie como los servicios turísticos populares se inserta en los flujos globales no hegemónicos, promoviendo el desplazamiento y la supervivencia de trabajadores informales en una economía popular transnacional. Para la construcción del trabajo, se utilizaron como herramientas metodológicas los contenidos teóricos, periodísticos y empíricos, teniendo como base la investigación etnográfica sobre el tema. La intención es discutir antropológicamente cómo el turismo popular está contenido en la globalización no hegemónica, en la medida en que se presenta como mercado de trabajo y herramienta de movilidad de los factores de producción transnacionales, en el ámbito de la informalidad.

Palabras-clave: Globalización no hegemónica, movilidad, turismo popular, trabajo.

\footnotetext{
${ }^{1}$ Artigo apresentado no I Congresso Internacional Online de Estudos sobre Culturas, na modalidade online, 2019.

${ }^{2}$ Doutora em Antropologia pela Universidade Federal de Sergipe; Coordenadora do Grupo de Pesquisa em Antropologia e Turismo - ANTUR/UFS/CNPQ; Docente do Departamento de Turismo e do Programa de PósGraduação Interdisciplinar em Culturas Populares da Universidade Federal de Sergipe; Brasil; e-mail: rosanaeduardo@yahoo.com.br.
} 


\begin{abstract}
The present article will seek to discuss the new configurations of the world of work in the ambit of globalization, having as an empirical field the popular tourism coming from the peripheries of Recife. The goal is to bring to light how popular tourist services are embedded in non-hegemonic global flows, promoting the displacement and survival of informal workers in a transnational popular economy. For the construction of the work, the theoretical, journalistic and empirical contents, based on ethnographic research, were used as methodological tools. The intention is to discuss anthropologically how popular tourism is contained in non-hegemonic globalization, insofar as it presents itself as a labor market and a tool for the mobility of transnational factors of production, in the sphere of informality.
\end{abstract}

Keywords: Non-hegemonic globalization, mobility, popular tourism, work.

\title{
1. Introdução
}

Os estudos sobre a globalização têm mostrado que tal processo está longe de ser concebido como linear e consensual. As concepções unilaterais que a concebem como fonte de padronização, apresentam-se improdutivas, sobretudo porque não dão conta das distintas dimensões políticas, socioculturais e econômicas que estão em jogo. Isso se deve ao fato de que a globalização é um fenômeno contraditório, diverso e conflituoso, produto de negociações e embates entre esferas globais e locais, que tem em sua composição rupturas e continuidades (GIDDENS, 1991). É composto por um processo dialético de duas forças e dois sentidos, em que a primeira é a força que a promove, constituída pelas empresas e instituições financeiras internacionais, e a segunda é formada pelas forças que resistem a essa hegemonia.

Nesse contexto, é possível identificar macroações que acontecem localmente, caracterizadora da globalização hegemônica, como também microações em âmbito global, desenvolvidas por indivíduos e grupos que promovem outras globalizações. O que se percebe é que os impactos locais da globalização não são uniformes, pois geram distintas dinâmicas dentro e entre os diferentes campos de mudanças. Por isso, torna-se fundamental ir de encontro às interpretações reificadas de modelos centralizadores de análise (LONG, 1996, p.37).

No estudo do contexto mundial, a Antropologia tem buscado dar conta das múltiplas globalizações que são instauradas, considerando suas relações de força e de poder. Assim, um dos âmbitos da disciplina passa a ser o de analisar como os pressupostos gerais lançados pela globalização hegemônica ganham novos contornos quando postos em prática no cotidiano local e regional (CAVALCANTI, 2004). Por isso, as trajetórias individuais vêm ganhando espaço no olhar antropológico, apresentando-se como estratégia de compreensão das 
totalidades sociais mais amplas. Dessa forma, o enfoque não está no sujeito, mas nas ações e microhistórias que se apresentam como unidade de observação sobre a sociedade contemporânea (AUGÉ, 1994; DE CERTEAU, 1998; SAHLINS, 2004).

Nesse sentido, o principal objetivo do artigo é discutir questões como globalização, mobilidade e mundo do trabalho, tendo como base empírica o turismo popular, denominação dada às práticas turísticas vivenciadas a custos reduzidos, que são elaboradas e desenvolvidas pela população de baixa renda que vive nas periferias do país. Hoje, essas práticas apresentam-se não só como uma atividade de lazer, mas também como um mercado de trabalho em constante crescimento, que se configura como complementação de renda para uns e principal fonte de rendimentos para outros. O estudo foi realizado por meio de pesquisa bibliográfica e de campo, utilizados como ferramentas metodológicas os conteúdos teóricos, jornalísticos e empíricos, seguindo uma abordagem etnográfica. Trata-se de parte das investigações e reflexões realizadas pela autora durante o doutorado no Programa de PósGraduação em Antropologia da Universidade Federal de Pernambuco.

\section{Mobilidades Turísticas Não-Hegemônicas}

A mobilidade contemporânea é um amplo espaço para a discussão da globalização nãohegemônica, já que os fluxos culturais globais - de pessoas, tecnologias, finanças, informações e ideologias (APPADURAI, 1998) - têm ocorrido dentro, fora ou nos interstícios da estrutura oficial. Neste sentido, os movimentos, os contatos e as viagens passam a ser cruciais para pensar o contemporâneo, visto que,

[...] a aceleração e intensificação do fluxo de pessoas em escala global não envolvem apenas atores grandiosos e com uma inclinação consciente para o transnacionalismo. Elas também criam um mundo onde uma quantidade maior de alteridades pode ser experimentada por atores sociais que não são necessariamente membros de elites econômicas e políticas. Entre estes destacam-se os turistas internacionais, os migrantes internacionais e os transmigrantes (RIBEIRO, 1997, p.20)

Por isso, uma das formas de compreensão dos deslocamentos humanos é o turismo, prática social encontrada em grande parte das sociedades e culturas, que tem estado cada vez mais presente na agenda de indivíduos das diversas classes sociais, adquirindo características e significados distintos. Milton Santos, em seu artigo intitulado "Lazer popular e geração de empregos" discute as possibilidades de geração de trabalho que constituem as formas populares de lazer. Conforme salienta o autor, o emprego em atividades vinculadas ao lazer 
não é exclusiva dos extratos sociais dominantes da sociedade, sendo produzidas também de baixo para cima, de forma permanente, criativa e gerando renda.

\begin{abstract}
Ao mesmo tempo em que, com a globalização da economia se modifica a organização da produção e mudam as condições do emprego e as condições do desemprego, criam-se novas atividades, inclusive essas ligadas ao tempo livre e ao lazer, que passam a constituir um fenômeno misto, porque participando como um setor importante da economia e porque vigorosa manifestação da cultura, opondo e reunindo cultura de massa e cultura popular, o mundo e o lugar, o mercado e a vida (SANTOS, 2000, p. 35).
\end{abstract}

A atividade apresenta-se também como um diversificado campo para pensar o plano simbólico da mobilidade, pela sua capacidade em evidenciar constituições de gosto, estilos de vida e disposições estéticas. Neste âmbito, o turismo pode ser visto tanto como prática, do qual os indivíduos e grupos sociais buscam se distinguir na hierarquia social, quanto como espaço, onde são constituídas e manejadas as fronteiras culturais e simbólicas entre as classes (BOURDIEU, 1983). Mas, o que se tem visto é que há uma desatenção sobre o papel das viagens turísticas nos arranjos econômicos, sociais e simbólicos das populações pobres, pelo fato dos segmentos de baixa renda raramente serem concebidos na categoria "turista". A presença desses estratos sociais no estudo sobre o tema no Brasil, normalmente é encontrada em pesquisas sobre os impactos da atividade em localidades receptoras ou sobre a classe trabalhadora do turismo convencional. Mas dificilmente são vistos como classe social capaz de planejar, produzir e consumir viagens turísticas.

O turismo popular é uma forma de mobilidade que se constitui como ferramenta para a movimentação de pessoas e mercadorias entre centros comerciais populares no Brasil e fora dele, produzindo trocas interculturais e fluxos transnacionais periféricos. Esse universo permite identificar questões ligadas à globalização, ao mundo do trabalho e a mobilidade, na medida em que absorve em seu interior experiências culturais territorializadas e desterritorializadas, constituídas por influências mundiais e produções locais, que dinamizam fluxos financeiros, humanos e de mercadorias.

Seus promotores e consumidores são constituídos por grupos de donas de casa e de igrejas, estudantes de escolas públicas, trabalhadores, membros de associações de bairro e sindicatos, grupos de amigos ou parentes. Nesse ambiente, há empresas, empreendedores, cooperativas, além de iniciativas individuais ou coletivas que garantem os deslocamentos para os mais diversos espaços, levando grupos para ambientes naturais e históricos, eventos culturais e 
religiosos, bem como centro de compras e diversão. Como é possível observar na entrevista com um empreendedor turístico a seguir:

\begin{abstract}
Eu vim da Bahia ao Recife, passar uma temporada de quinze dias. Aí me acostumei aqui. Cheguei aqui, enfrentei a vida de cobrador, passei três anos na Vera Cruz, trabalhei na Borborema. E saí e comecei negociando. E no mesmo instante, depois, comecei a fazer piquenique. Ia levar grupo para Natal, ia pra Maceió, ia para Aracaju. E depois comecei as excursões para Salvador, Fortaleza, Maceió, Paulo Afonso. E em seguida comecei fazendo também a sulanca. Como realmente emprego tá difícil, (...) fiz um jeito assim de manter minha vida nas viagens, como eu faço piquinique, faço as excursões, faço compras, que é a sulanca (Caruaru, Toritama, Santa Cruz) (...). Eu trabalho não só a sulanca, eu trabalho também muito na área pedagógica. Porque eu presto muito serviço aos colégios. Assim, tanto alugo ônibus, como eu faço também a organização. Assim, vou no colégio e fecho o pacote (LAÍLSON BAIANO).
\end{abstract}

A forma de organização das viagens não é exógena aos participantes, pois está entrelaçada ao estilo de vida de quem o vivencia. Trata-se de um turismo produzido artesanalmente, tecido pelas mãos não só do organizador, mas também dos participantes, que interferem no planejamento e na execução dos deslocamentos. Os espaços utilizados para a organização e captação dos viajantes ocorrem normalmente no próprio ambiente doméstico, nas ruas de bairros e municípios. A forma de divulgação ocorre através de classificados de jornal, panfletos espalhados em espaços públicos de intensa movimentação, pela comunicação boca a boca ou através de visitas domiciliares.

Muitos deles possuem um nome fantasia para intitular sua empresa e apresentá-la aos clientes, utilizando-se do próprio ambiente doméstico para empreender suas viagens. "A minha agência é a sua casa! Apenas utilizo-me de uma agenda de contatos e bato de porta em porta na casa das pessoas". Foi o que disse uma organizadora de viagem ao explicar como funciona a sua empresa, constituída não em espaço físico comercial, mas na interação, no contato entre as pessoas.

O ônibus é utilizado como importante meio de transporte dessa modalidade turística, podendo ser proveniente tanto da frota de transportadoras oficiais como das cooperativas de trabalhadores autônomos. Os ônibus particulares são envolvidos por elementos simbólicos, que muitas vezes são evidenciados por características encontradas na estrutura física, tais como: frases de efeitos colocadas nos vidros, forma de pintura e cores utilizadas, decoração interna, conservação, limpeza e nome-fantasia escolhido. 




Ônibus particulares de turismo Fonte: Acervo pessoal
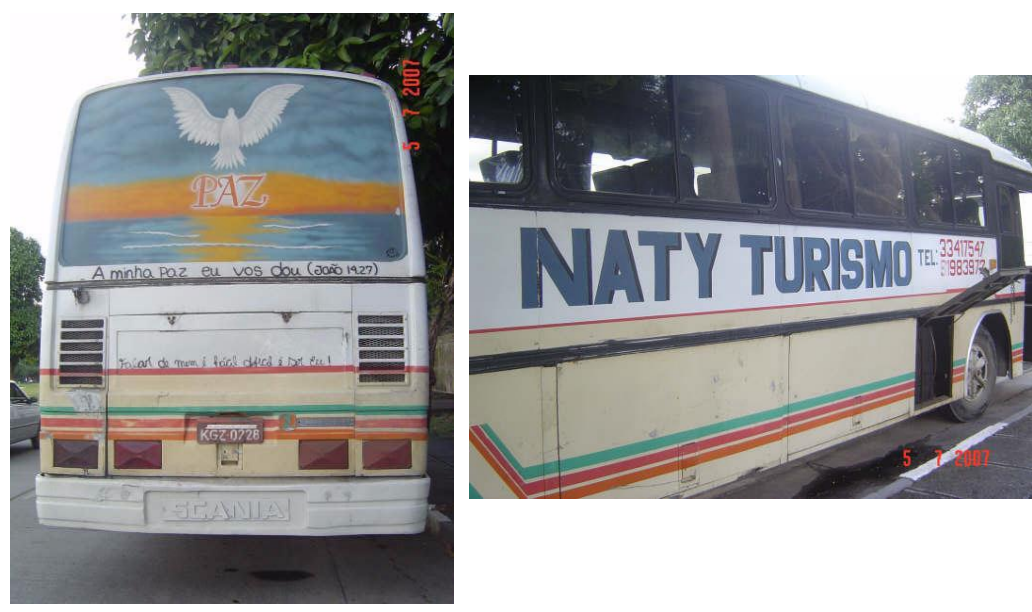

Tais transportes apresentam-se como uma peculiaridade dessa forma de experiência turística, já que são conduzidos pelos próprios donos, o que permite uma relação mais próxima com os grupos transportados. Muitas vezes são eles que além de transportar, planejam, divulgam e executam os deslocamentos, não havendo nesse caso mediadores. Seus proprietários são normalmente ligados a cooperativas que servem para despachar a documentação exigida oficialmente. Mas, como explica o proprietário do ônibus Venezatur: "Cada dono tem que correr para conseguir seu cliente. A gente mesmo cria a viagem e vende a passagem".

Urry (2001) descreve que na experiência turística há a troca do ordinário pelo extraordinário, na medida em que há um afastamento das práticas, redes e espaços sociais cotidianos em que o anonimato e a liberdade são experimentados. Mas o ambiente empírico do turismo popular sugere a relativização e problematização de tal pensamento, pois muitas vezes suas práticas vão de encontro à compreensão de distanciamento social e cultural vivido, contradizendo a busca do individualismo no ato de viajar.

Um bom exemplo disso foi o que pude observar quando acompanhava uma excursão ao espetáculo da Paixão de Cristo em Nova Jerusalém. O grupo em que eu estava foi até o teatro ao ar livre mas não assistiu o espetáculo, preferindo fazer um churrasco atrás do ônibus. Quando circulei no estacionamento percebi que existiam outros grupos fazendo o mesmo, inclusive composto por pessoas idosas, que explicaram não ter a menor condição de correr entre os palcos para assistir ao espetáculo. Ao conversar com um organizador de viagem que empreende deslocamentos para Fazenda Nova, ouvi a seguinte explicação: “A maioria não vem para o espetáculo, vem só para o passeio". 
É como se o turismo popular estivesse ligado ao sentido de pedaço, termo cunhado por Magnani (1984), utilizado como categoria abstrata e simbólica, que serve para designar os vínculos estabelecidos entre as pessoas participantes de redes de sociabilidade. $\mathrm{O}$ autor identifica o pedaço como uma terceira dimensão ${ }^{3}$, intermediário da casa e da rua (DAMATTA, 2000). A categoria pedaço tem estado constantemente presente na fala dos interlocutores, como segue abaixo:

Eu moro no Ibura, no Ibura de Baixo. Mas eu tenho gente em Muribeca, em Prazeres, como na outra área do Ibura que é muito grande, Ipsep e até na Cidade Universitária. (...) comecei em Muribeca. Eu cheguei no conjunto Muribeca, o quê, em 1984, quer dizer, estava recém inaugurado. Até o presente momento eu efetuo viagens ali dentro. Tem meninas ali que viaja comigo que às vezes eu nem sei quem é a menina, e, quando chegam, dizem: tu não me conhece mais não é? Devido ao conhecimento. Porque às vezes eram solteiras, já casaram, hoje já são mães, as fillhas já estão viajando comigo (LAÍLSON BAIANO).

O pedaço não depende diretamente do território, pois pode mover-se de acordo com os interesses do grupo - que também negocia continuamente as fronteiras de quem é e de quem não é do pedaço. Mas Magnani (1984) explica que não basta morar perto ou frequentar assiduamente certos lugares para ser considerado do "pedaço", é necessário estar situado numa rede particular de relações sociais dos quais estão inscritos elementos como parentesco, vizinhança e procedência.

\section{Quando a cultura viaja}

A mobilidade humana ganha novos contornos na contemporaneidade, sobretudo pela influência da globalização, da transnacionalização e do cosmopolitismo vivenciado tanto por fluxos transnacionais dominantes quanto pelos "supostos" dominados. Estes deslocamentos podem ser influenciados por fatores como classe, gênero, etnia e religião, bem como pelos distintos graus de liberdade. Trata-se de uma nova ordem mundial, que desestabiliza noções de identidade, pertencimento e autenticidade, produzindo complexas experiências de trabalho, moradia, comércio e lazer.

\footnotetext{
3 “O termo na realidade designa aquele espaço intermediário entre o privado (a casa) e o público, onde se desenvolve uma sociabilidade básica, mas ampla que é fundada nos laços familiares, porém mais densa, significativa e estável que as relações formais e individualizadas impostas pela sociedade" (MAGNANI, 1984, p. 138).
} 
Os fluxos humanos globais, livres e forçados estão pluralizando o fazer antropológico, na medida em que passam a exigir novos debates epistemológicos e investigativos, que deem conta das rotas e experiências culturais vivenciadas nestes deslocamentos. Nesse sentido, como defende Clifford (1999), a cultura além de estar circunscrita no território, passa a ser compreendida no sentido de trânsito e movimento.

Assim, pensar a cultura em termos globais é considerá-la como processo, buscando dar conta das produções culturais que não estão circunscritas no espaço. Um bom exemplo disso são os fluxos de pessoas, mercadorias, informações e imagens que promovem o que Featherstone (1990, p.07) denominou de "terceiras culturas", culturas transnacionais ou mesmo as chamadas comunidades "imaginadas” resultantes das interações sociais midiatizadas.

Em seu livro "Itinerarios Transculturales", Clifford (1999) defende que os sentidos de "morar" e de "estar em trânsito" precisam ser revisitados pela Antropologia, para que se possa entender o universo cultural dos deslocamentos contemporâneos. $\mathrm{O}$ autor problematiza a delimitação do campo enquanto tempo e espaço, visualizado em termos de fluxo e não de lugar fixo.

Para Clifford (1999), esses movimentos possibilitam vir à tona lugares de trânsito como supermercados, aeroportos e estacionamentos, bem como atores sociais envolvidos, tais como os peregrinos, turistas e migrantes, que muitas vezes são marginalizados nas concepções mais fechadas de cultura. Isso permite identificar historicidades, disputas e interações que vêm ocorrendo cotidianamente no mundo atual, quando o nativo se apresenta como um viajante no mundo globalizado.

O referido autor critica a etnografia tradicional por ter privilegiado as relações de residência em detrimento das relações de deslocamento. Para ele é necessário fazer estudos comparativos de dinâmicas de residência e de viagem, para que a cultura possa ser compreendida tanto em espaços fixos como de trânsito. É o que Sahlins (1997) chama de Cultura Translocal e Hall (2006) chama de Cultura Diaspórica, consideradas como culturas transculturais dispersas e unidas por uma contínua circulação de pessoas, ideias, objetos e dinheiro.

Nessa realidade de mobilidade cultural, a relação espaço-tempo é reconfigurada e impulsionada pelas tecnologias, afrouxando a relação entre a cultura e o lugar. Em todo o mundo, os fluxos migratórios, forçados e livres, estão pluralizando e construindo identidades 
culturais híbridas e múltiplas, desestabilizando os antigos Estados-nação. Por isso é que aspectos como mobilidade, movimento e fluxos são importantes ferramentas analíticas para a compreensão da vida social contemporânea.

Esses temas, sobretudo quando relacionados aos deslocamentos de pessoas em busca de melhores condições de vida e de trabalho, diariamente ganham novos debates, mecanismos de vigilância e ações criativas que resistem ao controle. Nesse cenário "móvel", há a proliferação das culturas cosmopolitas voltadas para a experiência, interação e sociabilidade em contextos culturais divergentes (FEATHERSTONE, 2000; HANNERZ, 1999), que envolve também o mundo do trabalho, como podemos observar a seguir:

\begin{abstract}
Dilson saiu de Salvador há 12 anos. Decidiu tentar a sorte de um emprego na cidade paraguaia conhecida pelos brasileiros como o paraíso das compras de importados. Hoje está casado e ganha US\$ 3 mil por mês em uma loja de eletrônicos. Dilson mora em Foz do Iguaçu (PR), do outro lado da Ponte da Amizade, e faz parte de um grupo de nordestinos que trabalha de forma regular nas lojas da região. O baiano tem toda a documentação paraguaia. O contrato foi assinado em dólar. Férias só uma semana por ano. $\mathrm{O}$ trabalho, por outro lado, vai de domingo a domingo. O comércio abre bem cedo e fecha às 17hs (Diário de Pernambuco, 03.06.2007).
\end{abstract}

Hannerz (1999), em seu artigo “Cosmopolitas e Locais na Cultura Global”, traz a discussão sobre o cosmopolitismo e as formas de mobilidade humana na contemporaneidade. Para o autor, o cosmopolitismo está relacionado à habilidade individual em interagir e apreender os sistemas de significados da cultura divergente. Conforme indica em seu texto, os fluxos humanos, tecnológicos e comunicacionais têm gerado novas formas de interações, capazes de produzir diversas culturas transnacionais, que muitas vezes transcendem as identidades nacionais. Mas adverte que a mobilidade humana tanto é capaz de potencializar as experiências cosmopolitas, como também minimizar tal envolvimento.

O turismo foi citado por Hannerz (1999) como experiência pouco estimuladora de experiências cosmopolitas. Os fluxos turísticos, segundo ele, muitas vezes são planejados justamente para distanciar-se dos "perigos" da imprevisibilidade do ambiente cultural visitado, sendo vivenciadas muitas vezes como "mobilidades controladas e previsíveis". Tal crítica também pode ser visualizada em teóricos como Maccannell (2003) e Bauman (1998).

Na opinião de Maccannell (2003, p.15), a crítica diante dos turistas não está relacionada ao deslocamento em si. O que tem sido amplamente questionado são as formas de interação que são realizadas nestas formas de viagens, resultantes de experiências superficiais diante das culturas e territórios do Outro. Conforme o mesmo autor, o que incomoda os intelectuais é a 
apreciação pouco profunda do olhar do turista em relação aos espaços e pessoas visitadas e as consequências que esse comportamento gera nas localidades anfitriãs.

Mas a globalização tem distintos efeitos diante da liberdade dos fluxos de comércio, de pessoas e de negócios financeiros, gerando um importante fator de estratificação na sociedade de consumo, conforme salienta Bauman (1999). Ele esclarece que a efetiva liberdade para tais movimentos está "estruturalmente" destinada às elites, não ocorrendo o mesmo com grande parte da população. “[...] os que vivem no 'alto' estão satisfeitos de viajar pela vida segundo os desejos do seu coração, podendo escolher os seus destinos de acordo com as alegrias que oferecem. Os de 'baixo' volta e meia são expulsos do lugar em que gostariam de ficar" (BAUMAN, 1999, p.95).

Essa premissa pode ser ampliada na observação sobre as formas de circulação dos indivíduos entre países e continentes. Se por um lado as nações mais ricas possibilitam aos seus cidadãos a livre circulação e o exercício do cosmopolitismo e da extraterritorialidade no interior de seus territórios, como ocorre com a União Europeia, por outro lado intensificam o controle diante dos fluxos de pessoas provenientes dos países mais pobres, cuja migração é movida em grande parte pelas relações de trabalho e busca de melhoria de vida.

Diante do fluxo migratório, os Estados-nação dos países ricos têm imposto severas restrições sobre tal movimento, utilizando-se da criminalização como alternativa para conter, controlar e punir os "fluxos indesejados". Um bom exemplo disso é a lei de imigração que foi aprovada pela União Europeia em 18 de junho de 2008. Seu principal objetivo é a intensificação das punições aos imigrantes ilegais, prevendo a detenção dos mesmos por um período de até 18 meses, além da expulsão e a respectiva proibição de retorno à Europa nos cinco anos seguintes ${ }^{4}$.

A mobilidade é vista por Bauman (1999) como um valor, uma experiência cobiçada e requerida por grande parte da população, mas não alcançada por todos. Fato que provoca um grande abismo na escala da liberdade entre os que são estimulados a mover-se e os que estão "fadados" a não circulação, alvo dos controles. O que causa a emergência de uma hierarquia da mobilidade, que absorve em seu interior privilégios e privações no deslocamento humano.

\footnotetext{
4 “Governo brasileiro 'lamenta' nova lei europeia para imigração. Reportagem publicada em 18.jun.2008 pela Folha de São Paulo online. Disponível em: 〈http://www1.folha.uol.com.br/folha/mundo/ult94u413765.shtml?>. Acesso em 07.07.2008.
} 
Para discutir essa hierarquia, Bauman (1998) lança mão de duas metáforas de viajantes constituídas nas figuras do turista e do vagabundo. O paradigma do turista representa a ideologia hegemônica da globalização, posição em que estão os países ricos e as organizações transnacionais, que encontram poucas barreiras na circulação pelo mundo afora. Tal paradigma representa os fluxos humanos, de mercadorias, financeiros e tecnológicos, que possuem plena liberdade no ato de mover-se, representando as formas de deslocamentos aceitáveis e autorizadas dos sistemas mundiais e nacionais de controle.

Os vagabundos representam os fluxos "inconvenientes" e marginais perante a estrutura dominante. Posição em que são encontradas grande parte da população mundial, composto por àqueles que estruturalmente não foram dados o direito de serem turistas, constituídos pelas margens e os fluxos periféricos. São as mobilidades precárias vivenciadas por trabalhadores, migrantes e toda a sorte de pessoas que se movem inclusive na informalidade e na ilegalidade que, diferentemente dos turistas, nem sempre estão em movimento por escolha própria. Muitas vezes o desenraizamento ocorre por necessidade de mover-se para sobreviver, como muitos trabalhadores que circulam cotidianamente entre fronteiras interestaduais, internacionais e intercontinentais, atuando no mercado de trabalho informal.

Os passeios e viagens turísticas populares muitas vezes apresentam-se na posição de alter ego do paradigma do turista, sendo banidos pelos vários segmentos turísticos convencionais, compostos pelas empresas turísticas oficiais, prefeituras municipais, moradores de segunda residência e comerciantes locais. É como se o Turismo Popular estivesse situado numa posição liminar (TURNER, 1974), estigmatizado como turismo de "pobre", de "farofeiro", constituídos por aqueles que ocupam os degraus mais baixos da estrutura social.

Por consumirem pouco nos locais visitados são conhecidos pejorativamente como "farofeiros", denominação dada no Brasil aos que se alimentam fora do lar com alimentos provenientes de casa. Por isso, são frequentemente alvos de políticas públicas cujo principal objetivo é restringir o acesso aos principais espaços naturais "turísticos", através de cobranças monetárias que envolvem inclusive propinas.

Em novembro de 2006, o Jornal do Commercio publicou uma reportagem intitulada "Cobrança de taxa em praias causa tumulto", que descrevia a aplicação de uma taxa ambiental cobrada aos visitantes das praias de Suape. O curioso é que tal cobrança foi utilizada principalmente para inibir as populações pobres que ali se dirigiam, visto que apenas 
os ônibus populares de turismo foram obrigados a pagá-la. Enquanto isso, outros visitantes estavam isentos, como as pessoas que utilizavam carros de passeio ou ônibus de operadoras turísticas oficiais. Essa situação atingiu diretamente a população de baixa renda, como observamos no trecho da reportagem a seguir:

(a) O carteiro Gildo Queiroz estava na excursão que saiu de Vitória de Santo Antão, na Zona da Mata, às 6h30, com destino à Praia de Enseada dos Corais. Havia 48 pessoas no coletivo. 'Pagamos R\$15 pelo passeio. Não temos dinheiro para a taxa de R\$ 151. É abusivo', comentou Gildo.

(b) 'Queremos apenas nos divertir. Cada pessoa gastou R \$ 10 para vir até Suape. Se iriam cobrar a taxa, que avisassem antes', afirmou a doméstica Ivanilde Silva, que estava com o marido e os dois filhos e fazia parte de um grupo do Ibura, na Zona Sul da capital.

Mas no ambiente empírico, as metáforas do turista e do vagabundo não são distantes uma da outra, mesclando-se de acordo com a manipulação de seus agentes. Há uma variedade de experiências de mobilidade que possuem características dos dois paradigmas, não sendo concebidos, portanto, como propostas estanques de se pensar o deslocamento humano.

\section{Deslocando-se para sobreviver}

Nas duas últimas décadas, o mundo do trabalho absorveu um conjunto de mudanças estruturais, tecnológicas, produtivas e organizacionais desencadeadas pela emergência de uma nova divisão internacional do trabalho. Tal realidade surge como resultado de um conjunto de estratégias produtivas e empresariais, que alteraram objetivamente e subjetivamente a relação entre trabalhadores, empregadores, Estados, capitais financeiros e meios de produção.

A globalização trouxe em seu cerne o que chamou Harvey (1989) de acumulação flexível, caracterizada pelo surgimento de novas maneiras de produção e distribuição no âmbito mundial, como resultado das inovações tecnológicas, organizacionais e comerciais. Nas localidades, ocasionou uma redefinição da noção de trabalho, devido à proliferação de opções temporárias e terceirizadas de contratação, bem como a ampliação da informalidade e da fragmentação da vida econômica (LONG, 1996, p.38).

A ampliação de opções parciais, temporárias, terceirizadas e informais de contração causou perdas significativas para a classe trabalhadora, favorecendo o aumento de formas alternativas de geração de emprego e renda, como possibilidade de redução dos altos índices de 
desemprego e da consequente exclusão social (RAMALHO \& SANTANA, 2003). Com a crise do mercado formal de trabalho e de serviços sociais e culturais regulares, o que se tem hoje é um espaço de criativas possibilidades de sobrevivência.

Trata-se de uma pluralidade de intervenções que emergem no interior de uma economia popular, que vem dando respostas à realidade de diversas periferias do Brasil, melhorando e transformando a realidade social local. Tais intervenções chegam como possibilidade de preenchimento das lacunas deixadas pelo Estado e a impossibilidade de inserção dos membros da comunidade no sistema mercantil mais amplo. Essa realidade tem sido constantemente observada no ambiente empírico do turismo popular, como é possível verificar no trecho da entrevista de um organizador de viagem:

\begin{abstract}
A gente entra hoje, pega um tempo, daqui a pouco tá na rua. [...] Como eu fiquei desempregado, comecei a vender jóia, depois de algum tempo a vender roupa e a fazer uns piqueniques, aí me adaptei a essa parte. Me manter, por minha conta mesmo. Eu faço minha renda. Anoto todas às vezes se eu tenho prejuízo ou tenho lucro. Eu vou anotando. No final do mês eu faço minha conta de quanto eu ganhei e quanto eu paguei. Eu faço o grosso e faço o líquido, né. Pra saber se eu realmente tô tendo lucro ou tô tendo prejuízo. Mas graças a Deus tá sendo melhor pra mim, trabalhar pra mim do que de empregado (LAILSON BAIANO).
\end{abstract}

A socióloga do trabalho Helena Hirata (MARIUZZO, 2006) explica que a peculiaridade do Brasil em enfrentar o desemprego está no papel desempenhado pelas redes de solidariedade formadas pela família, igrejas e vizinhos. Esse universo de produção, troca e consumo tem gerado uma economia dos setores populares, que mesmo dispersa e fragmentada, passou a constituir-se como um espaço de produções individuais, familiares e associativas, de circulação de produtos, serviços, pessoas e recursos, orientada por redes locais, de reciprocidade e vizinhança. São práticas econômicas complexas e diversas, elaboradas como busca de soluções cotidianas de sobrevivência e redução da exclusão social.

No Brasil, essa economia periférica absorve grande parte da população pobre, desempenhando importante papel de melhoria da qualidade de vida de seus produtores e usuários. Isso se deve pela intensa ligação estabelecida com o cotidiano e a real necessidade dos seus atores sociais, apresentando-se como ferramenta viabilizadora de acesso em termos de moradia, alimentação, saúde, educação, transporte, vestuário, microcrédito e lazer (MOTTA \& SCOTT, 1983). Trata-se de

[...] um sistema estruturado de empregos, altamente hierarquizado e especializado que, embora reflita as relações de trabalho capitalistas, também possui sua lógica própria. Afinal, no momento em que esta cadeia encontra-se um tanto descolada dos 
contratos formais e da regulamentação do Estado, acaba desenvolvendo suas próprias leis e regras (MACHADO, 2004, p.115).

É uma economia com identidade própria, germinada de dentro para fora e de baixo para cima, reflexo do ambiente ao qual é brotada (ARROYO, 2003, p.56). Constitui-se como um enfrentamento de uma maioria diante da macroeconomia vigente, sendo constituída por arranjos sociais e estruturas de emprego, renda e consumo.

Nesse ambiente econômico, popular e informal, o olhar antropológico traz importante contribuição. Isso porque, o próprio sentido de maximização e lucro é relativizado, pois tais fatores são observados não só por questões mercadológicas, monetárias ou de utilização dos bens, mas também pela busca da maximização de relacionamentos, de dádivas e de ampliação de redes de reciprocidade.

A Antropologia Econômica concebe as operações econômicas como um conjunto de processos socioculturais realizados nas distintas sociedades, problematizando as concepções deterministas da Economia e possibilitando outros olhares sobre o tema. A disciplina se interessa em compreender não apenas a economia da sociedade capitalista Ocidental mas também a de outros povos, considerando que as práticas econômicas não acontecem apenas na esfera do mercado mas também em outros contextos, como os domésticos e informais, por exemplo (DOUGLAS \& ISHERWOOD, 2004).

Para a Antropologia, "as relações de trabalho capitalistas, para além de suas acepções economicistas, são, fundamentalmente, relações culturais inscritas no cotidiano das pessoas", capazes de evidenciar princípios e valores (MACHADO, 2004, p.112). Trata-se de um elemento estruturador de relações sociais capaz de desempenhar papel ideológico, simbólico e prático com capacidade de construir identidades, redes de sociabilidades e mecanismos de distinção.

No estudo sobre o mundo do trabalho na população de baixa renda, a análise antropológica permite ampliar as concepções de trabalho e trabalhador, na medida em que possibilita investigar as estratégias de sobrevivência acionadas pelos indivíduos que envolvem informalidade, arranjos familiares, microempreendimentos de unidades domésticas e toda a sorte de possibilidades. Os estudos etnográficos sobre o assunto têm possibilitado observar a diversidade cultural no interior do universo do trabalho em que o indivíduo se apresenta não apenas como mão-de-obra, mas também como agente social, cultural, político e econômico. 
No contexto do turismo popular, como campo do trabalho, é necessário lançar mão das linhas teóricas que consideram as globalizações que são produzidas dentro do sistema hegemônico, constituídas por mercados e fluxos de pessoas provenientes do povo e não das elites. Trata-se de uma ferramenta que permite dar visibilidade as práticas cotidianas dos agentes periféricos populares que "subvertem" a estrutura como forma de sobrevivência. Por isso, utilizamos as perspectivas teóricas tratadas por Gustavo Lins Ribeiro sobre a globalização popular, considerada como

[...] sistema mundial no-hegemónico: una composición de varias unidades ubicadas en distintos lugares, conectadas por agentes activos en la globalización popular. La globalización popular está formada por redes que operan de manera articulada y que en general se encuentran en distintos mercados que forman los nudos del sistema mundial no-hegemónico. Esta articulación crea interconexiones que dan un carácter sistémico a este tipo de globalización y hace que sus redes tengan alcance a larga distancia. El sistema-mundial no hegemónico conecta distintas unidades en el mundo a través de flujos de información, personas, mercancías y capital (RIBEIRO, 2007, p. 15)

Mas de que forma o turismo popular insere-se nas redes de mercados e fluxos populares transnacionais? Para responder tal questionamento, teremos como base empírica o polo de confecção e moda popular localizado no agreste pernambucano ${ }^{5}$. Atualmente, a região é responsável por considerável dinamização da economia e do mercado de trabalho popular, tendo como principais polos os municípios de Toritama, Caruaru e Santa Cruz do Capibaribe. Diariamente as respectivas localidades recebem pessoas de várias partes do Nordeste, do Brasil e até de outras nações como Cabo Verde e Senegal.

A rota da moda popular pernambucana tem potencializado também o comércio informal, favorecendo inúmeros microempreendedores que frequentemente deslocam-se para tais localidades, como podemos observar a seguir:

Há dez anos, a sulanqueira Veronice Souza, 47, deixa, uma vez por mês, a cidade de Remando, na Bahia, em direção a Caruaru. A exaustiva jornada começa às $10 \mathrm{~h}$ da segunda-feira e só termina às $2 \mathrm{~h}$ da quarta-feira. As noites mal dormidas na poltrona do ônibus e a dureza da viagem parecem indiferentes diante da necessidade de alimentar a família. 'É muito sofrimento, mas é a vida', conforma-se ${ }^{6}$.

\footnotetext{
5 "Desde a década de 70, novas atividades vêm assumindo um papel econômico importante na região, que envolve não só a produção - de roupa (sulanca), de bordados e renda, de artesanato de barro - como também, especialmente, a comercialização dessa produção, através da criação e do incremento de feiras livres - a Feira da Sulanca, em vários locais do Estado, e a Feira de Caruaru. Os eventos turísticos, incentivados pelo poder público em associação a promotores privados, que, em geral, envolvem vários municípios, extrapolando, em alguns casos, a Região de Desenvolvimento onde eles se localizam, também contribuem para a criação de novas oportunidades de trabalho na região" (LYRA, 2005, p.147).
}

\footnotetext{
6 “Sulanqueiros na Rota do Medo". Jornal do Commercio, Caderno Cidades, 25.03.2007.
} 
As mercadorias são adquiridas para serem vendidas em bairros, ruas dos centros de capitais e cidades interioranas, bem como lojas do comércio formal. Mas além desses fluxos que chegam ao local há também os que se deslocam para outros centros comerciais, como forma de distribuição das confecções pernambucanas e compra de novas mercadorias para revenda no estado, interligando-se aos mercados populares nacionais e internacionais. As mercadorias produzidas para serem vendidas neste circuito são produzidas com baixo custo e pouca vida útil, com reduzida qualidade e durabilidade, que conduz a uma aceleração na produção, circulação e consumo.

Para viabilizar os fluxos de pessoas e mercadorias há uma ampla infraestrutura de serviços turísticos populares, em forma de transportes, agências de viagens, guias de turismo e meios de hospedagem, que tem possibilitado a viagem de diversos microempreendedores. É uma ferramenta que promove o fluxo cotidiano de sacoleiros, vendedores ambulantes e toda sorte de atividades informais no âmbito da compra, venda e consumo de produtos, serviços e tecnologias multiculturais e transnacionais (MEDEIROS \& LEAL, 2007).

Ao acompanhar um grupo em direção a Toritama e Santa Cruz do Capibaribe em julho/2008 pude observar um pouco da dinâmica do fluxo de pessoas e do comércio de confecções do agreste pernambucano. Mesmo tendo visitado o local no final do mês, período de pouco movimento segundo os interlocutores, foi possível perceber a intensa presença de pequenos comerciantes que chegavam para percorrer lojas, stands e barracas em busca de preços baixos e boas mercadorias. Alguns vinham de longe, como os provenientes de municípios da Bahia e Espírito Santo, enfrentando longas jornadas de viagens para adquirir mercadorias e vender nos lugares de origem.

Saímos às 03h50 da manhã de uma segunda-feira para chegar cedo a Toritama e depois seguirmos para Santa Cruz do Capibaribe. No retorno, que ocorreu por volta às $13 \mathrm{~h}$ do mesmo dia ainda paramos em fábricas de confecção localizadas na beira da estrada, onde as passageiras complementaram as respectivas compras.

Para fazer tal deslocamento contratei o serviço de um "fretante", como assim se intitula Laílson Baiano, morador de Ibura de Baixo, que sobrevive de organizar viagens há 23 anos. 
Localizei-o através de anúncio em classificados do jornal. Suas viagens envolvem centros de compras, visitas pedagógicas e práticas de lazer (piqueniques, shows, festas e excursões).

O grupo que acompanhei era formado por sete mulheres ${ }^{7}$, todas pequenas comerciantes provenientes de bairros como UR-10, Ibura de Baixo, Muribeca e Moreno. Segundo elas, a ida a rota da moda acontece semanalmente ou quinzenalmente para dar suporte à comercialização de confecções - cujas vendas ocorrem em domicílio, no próprio bairro e fora dele ou através de lojas no ambiente doméstico ou em centros comerciais.

O deslocamento para comprar roupas é desgastante por vários fatores. O horário de saída de casa; à distância a ser percorrida; o perigo de roubo nas estradas; as inúmeras lojas e barracas a serem visitadas; e as idas e vindas ao ônibus para deixar as mercadorias, que são carregadas em sacolas e/ou carrinhos.

As rotas comerciais do turismo popular agregam em seu interior formas lícitas e ilícitas de deslocar pessoas, mercadorias e recursos financeiros entre fronteiras, inserindo-se no interior de uma globalização popular (RIBEIRO, 2007). Isso é possível ser visto entre os municípios do polo pernambucano de confecções, formados pelos municípios de Toritama, Caruaru e Santa Cruz do Capibaribe e outros centros de comércio popular como o Brás (SP), a 25 de março (SP) e Ciudad Del Este (Paraguai), que juntos permitem a compra, a venda e a distribuição de produtos pernambucanos, chineses e paraguaios, pelas mãos de diversos trabalhadores do mercado informal.

Todas as sextas-feiras, um posto de gasolina de Caruaru, localizado às margens da BR-104, transforma-se numa verdadeira rodoviária pirata com dezenas de ônibus clandestinos partindo para o Sul e Sudeste do país, sobretudo São Paulo. Pelo menos três desses ônibus fazem viagens regulares para Foz do Iguaçu, no Paraná, viabilizando a atividade de um novo tipo de mascate cada dia mais comum em Caruaru: o sulanqueiro-muambeiro. São dezenas de homens e mulheres que duas vezes por mês enfrentam três dias de viagem para vender as roupas produzidas em Santa Cruz do Capibaribe e comprar brinquedos, fitas cassete e toda a sorte de

\footnotetext{
${ }^{7}$ A intensa presença feminina foi observada não só no grupo que acompanhei, mas também nos ônibus e vans que chegavam continuamente nos espaços pesquisados. Conforme Laílson Baiano, "[...] hoje a mulher sempre negocia mais que o homem", sendo $99 \%$ do seu público nas viagens para os polos de confecção. "Eu venho aqui nessa van com quinze pessoas. Às vezes não vem nenhum homem, só vem mulher. A frequência mais é mulher”, conforme o interlocutor. Segundo o grupo que viajou comigo, homem não entende de moda, por isso, confecção é negócio de mulher! De acordo com uma das interlocutoras, "a gente vê na televisão, aí sai uma moda, sai uma blusa, sai um short, e homem não entende. Se você manda comprar, ele vai perguntar que short é. Pra quê que serve.
} 
bugigangas em Ciudad del Este, paraíso da muamba, vizinho a Foz do Iguaçu (LYRA, 2005, p.144).

Nesse contexto, surge a categoria "sulanqueiro-muambeiro", que é um misto de viajante, trabalhador e agente transnacional. Esses trabalhadores informais atuam como agentes nãohegemônicos, que através de suas atividades e ações cotidianas, desafiam a economia global, apresentando-se como “conectores de espaços globais fragmentados” (RIBEIRO, 2006, p.14).

O sulanqueiro-muambeiro é um agente econômico emblemático no uso da infraestrutura turística popular, composto muitas vezes de trabalhadores egressos de empresas formais, desempregados, comerciantes ou microempreendedores que possuem lojas no setor formal (RODRIGUES, 2007, p.132).

Para a atividade de compra, distribuição e consumo das mercadorias outros trabalhadores e atividades entram em cena, podendo variar de acordo com o cenário pesquisado. Nas viagens destinadas aos polos comerciais podemos destacar categorias de viajantes mais frequentes, que são os turistas de compras e os diversos trabalhadores (sacoleiros, camelôs, vendedores ambulantes, entre outros).

O turista de compras é aquele que mescla motivações turísticas com as de aquisição de bens. Estes últimos normalmente são adquiridos para consumo doméstico e não comerciais. $\mathrm{O}$ sacoleiro pode ser "supostamente um turista de compras" quando se utiliza astuciosamente dessa categoria como estratégia de entrada, circulação e saída dos centros de compras. Mas ele é, antes de tudo, um empreendedor que viaja com objetivo de adquirir mercadorias para revendê-la no local de origem. É um comerciante que se utiliza de infraestrutura turística para desenvolver seu trabalho, cujo principal meio é a viagem, o deslocamento. A motivação dos vários outros trabalhadores que participam desses trajetos, como sulanqueiros, camelôs e laranjas têm como motivação o comércio informal, o que difere do viajante turista.

Nesse cenário é possível averiguar como o processo de precarização do trabalho abre espaço para soluções que possam substituir os postos de trabalhos que se reduzem a cada dia. Por isso, é necessário dar visibilidade às ações e os atores que se instauram na informalidade. Já que, como pontua Machado (2004, p.111), “a globalização só existe no conjunto das práticas de homens e mulheres que a criam, a vivem e a reinventam". 
Essa rota periférica transnacional de pessoas, dinheiro e mercadorias entre Pernambuco e Paraguai permite que as roupas confeccionadas no agreste nordestino possam ser facilmente encontradas nas ruas de Ciudad Del Este, correspondendo a 30\% dos vestuários vendidos no local. Quando chegam ao Paraguai são adquiridas por microempreendedores de lojas, bancas e bazares situados no interior do país, que compram em grande quantidade para vender a varejo (JC, 2000).

Quando chegam em Pernambuco, as mercadorias seguem para serem distribuídas na Feira do Paraguai, em Caruaru, onde existe muitos trabalhadores que ganham a vida comercializando tais produtos. Grande parte dos produtos importados é falsificada e de origem paraguaia ou chinesa, abarcando desde brinquedos, eletrônicos, eletrodomésticos, miudezas e objetos de decoração até remédios. Um exemplo disto é o medicamento Pramil, um modelo similar ao Viagra fabricado no Paraguai, que teve sua comercialização proibida no território brasileiro desde 2002, mas que é transportado clandestinamente para Pernambuco na rota sulancamuamba, para ser vendido no agreste e sertão do estado ${ }^{8}$.
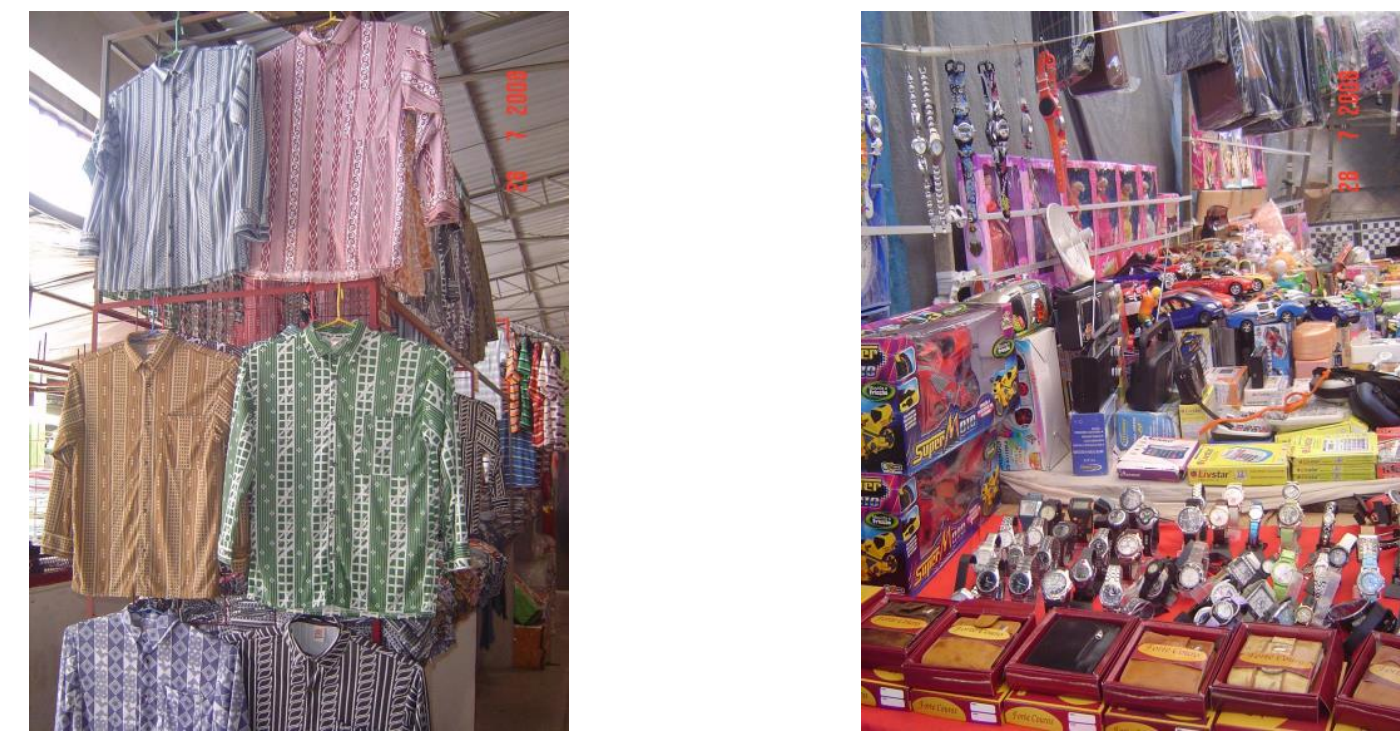

Exemplos de mercadorias transportadas entre Pernambuco e Paraguai Fonte: Acervo pessoal

As mercadorias são compradas tanto por comerciantes e consumidores do interior pernambucano quanto por pessoas de estados vizinhos (JC, 2000). Além disso, tais mercadorias também abastecem camelôs e vendedores ambulantes de todo o estado. Trata-se

\footnotetext{
8 Reportagem: "Viagra paraguaio invade interior". In: <http://acertodecontas.blog.br/atualidades/viagraparaguaio-invade-interior/>. Acesso em: 07.08.2008
} 
de uma mobilidade astuciosa, dispersa e silenciosa, estando continuamente se apropriando do que lhe é imposto e fazendo bricolagens com e na economia cultural dominante. Esses fluxos populares produzem uma estética errante, temporária e fragmentada com oscilações de formas e conteúdos (FEATHERSTONE,1990) com ações, procedimentos e operações multiformes que compõem uma antidisciplina no ato de mover-se.

\section{Conclusões}

Como foi discutido anteriormente, a infraestrutura turística popular cada vez mais tem sido utilizada para possibilitar o deslocamento de migrantes, trabalhadores e desempregados em busca de fonte de renda, sendo muitas vezes utilizada clandestinamente. A mobilidade turística das classes populares pode absorver lógicas de consumo constituídos por escolhas e usos de bens materiais e simbólicos provenientes da junção de capital cultural e social, posição dos indivíduos na estrutura social e disposição estética. Tal prática é capaz de revelar muito das condições materiais de existência, dos sistemas éticos e estéticos, bem como das lógicas e preferências dos seus usuários.

A singularidade dessa modalidade turística reside na capacidade de ora se moldar, ora subverter e ora estabelecer vínculos com outras formas do Turismo do mundo capitalista. Por isso, acreditamos que esse conjunto de práticas produz uma cultura de deslocamento com distintas formas de produção, circulação e apropriação, que conduz a outras formas de socialização e uso do espaço. São nessas fronteiras que emergem novos sujeitos, tradições e identidades, bem como comunidades e consumidores estigmatizados, que criativamente arranjam formas de participar desse fenômeno global. O cotidiano é o ambiente cultural propício para a sobrevivência desses arranjos populares alternativos diante da precarização do sistema de empregabilidade formal, onde são inventadas as mil maneiras de "caça" não autorizada (DE CERTEAU, 1998).

A importância do olhar antropológico sobre a trilogia globalização, mobilidade e mundo do trabalho está em observar como tais categorias são absorvidas, vivenciadas e manipuladas no cotidiano dos trabalhadores-viajantes. E o universo dos motoristas, sacoleiros, comerciantes, laranjas, fretantes e guias de turismo, que se encontram envolvidos na rota de comércio popular transnacional entre Pernambuco, São Paulo, Paraná e Paraguai ajudam a pensar isso. Essas práticas comerciais e seus circuitos subterrâneos de circulação embaralham fronteiras 
regionais e nacionais, desafiam o controle dos Estados-nação e aproximam territórios supostamente distantes, como Toritama e Ciudad Del Este.

Consideramos que esta forma de turismo se insere no universo do consumo precário, caracterizado menos pela restrição de bens do que pela forma como ocorre à sua viabilização nos ambientes pobres. São dispositivos informais que permitem levantar recursos e baratear os produtos, aparecendo facilmente nas escolhas materiais circunscritas no vestir, nas habitações e nas opções de lazer. Neste âmbito, apresenta-se como uma tentativa viável de inclusão social, que assume "[...] um valor de resistência à degradação e ao esgarçamento dos vínculos sociais que rondam a vida dos pobres no cotidiano" (CASTILHO, 2006, p.144).

\section{Referências}

APPADURAI, Arjun. "Disjunção e diferença na economia cultural global" In: Featherstone, Mike (coord.). Cultura Global: nacionalismo, globalização e modernidade. 2.ed. Petrópolis, RJ: Editora Vozes, 1998, p.311-327.

ARROYO, João. “Economia Popular e Solidária”. In: MEDEIROS, Alzira; MARTINS, Paulo Henrique (orgs.). Economia Popular e Solidária: desafios teóricos e práticos, 2003, pp.51-58.

AUGÉ, Marc. Hacia uma Antropologia de los mundos contemporaneos. Barcelona: Gedisa, 1994.

BAUMAN, Zygmunt. O mal-estar na pós-modernidade. Rio de Janeiro: Jorge Zahar, 1998.

Ed., 1999.

Globalização: consequências humanas. Rio de Janeiro: Jorge Zahar

BOURDIEU, Pierre. "Esboço de uma Teoria da Prática". In: ORTIZ, Renato (org.). Pierre Bourdieu. São Paulo: Ática, 1983.

CASTILHO, Sérgio. "Memória, experiência urbana e consumo entre famílias populares no bairro do Jacintinho, Maceió, Nordeste do Brasil". In: LEITÃO, Débora K.; OLIVEIRA LIMA, Diana Nogueira de.; MACHADO, Rosana Pinheiro. Antropologia do consumo: diálogos entre Brasil e Argentina. Porto Alegre: AGE, 2006, pp.141-157.

CAVALCANTI, Josefa Salete B. "Globalização e processos sociais na fruticultura de exportação do vale do São Francisco". In: CAVALCANTI, Josefa Salete B.(org.) Globalização, Trabalho, Meio Ambiente: Mudanças socioeconômicas em regiões frutícolas para exportação. INPSO, Instituto de Pesquisas Sociais, FUNDAJ, Fundação Joaquim Nabuco, Recife, Pernambuco, Brasil, 2004. Disponível em: <http://sala.clacso.org.ar>. Acesso em: 25.05.08. 
CLIFFORD, James. Itinerarios transculturales: el viaje y la traducción a fines del siglo XIX. Barcelona: Gedisa, 1999.

DA MATTA, Roberto. A Casa \& a Rua. Rio de Janeiro: Rocco, 2000.

DE CERTEAU, Michel de. A invenção do cotidiano: 1. artes de fazer. $3^{\mathrm{a}}$ ed. Petrópolis, RJ: Vozes, 1998.

DOUGLAS, Mary; ISHERWOOD, Baron. $O$ mundo dos bens: para uma antropologia do consumo. Rio de Janeiro: Editora UFRJ, 2004.

FEATHERSTONE, Mike. "A Globalização da Mobilidade: experiências, sociabilidade e velocidade nas culturas tecnológicas". In: Lazer numa sociedade globalizada. São Paulo: SESC /WRLA, 2000, p.47-111.

São Paulo: Studio Nobel: SESC, 1990.

O desmanche da cultura: globalização, pós-modernidade e identidade.

GIDDENS, Anthony. As Consequências da Modernidade. São Paulo: Ed Unesp, 1991.

HALL, Stuart. Da Diáspora: identidades e medições culturais. Belo Horizonte: Editora UFMG, 2006.

HANNERZ, Ulf. "Cosmopolitas e Locais na Cultura Global”. In: FEATHERSTONE, Mike. (Org.). Cultura Global: nacionalismo, globalização e modernidade. Rio de Janeiro: Vozes, 1999.

HARVEY, David. Condição pós-moderna. 14ª ed. São Paulo: Ed. Loyola, 1989.

JORNAL DO COMMERCIO. "Cobrança de taxa em praias causa tumulto". In: Caderno Cidades. Reportagem publicada em 16.nov.2006.

LONG, Norman. "Globalization and localization: new challenges to rural research". In: MOORE, Henrietta (ed.). The future of anthropological knowledge perspectives. London: Routledge, 1996, pp. 37-59.

LYRA, Maria Rejane Souza de Britto. "Sulanca X Muamba: rede social que alimenta a migração de retorno". In: São Paulo em Perspectiva, v. 19, n. 4, out./dez. 2005, pp. 144-154.

MACCANNELL, Dean. El turista: una nueva teoría de la clase ociosa. Barcelona: Melusina, 2003 [1976].

MACHADO, Rosana Pinheiro. "A garantia soy yo": etnografia das práticas comerciais entre camelôs e sacoleiros nas cidades de Porto Alegre (Brasil) e Ciudad Del Este (Paraguai). Dissertação apresentada no Programa de Pós-Graduação em Antropologia Social da Universidade Federal do Rio Grande do Sul. Porto Alegre, 2004, 143 p.

MAGNANI, José Guilherme. Festa no Pedaço: cultura popular e lazer na cidade. São Paulo: Ed. Brasiliense, 1984. 
MARIUZZO, Patrícia. Socióloga discute o desemprego e a questão de gênero no mundo do trabalho. Inovação Uniemp , Campinas, v. 2, n. 5, 2006.

MEDEIROS, Bartolomeu F.; LEAL, Rosana E.S. "Patrimônio Cultural, Identidades e Globalização Popular; um estudo de caso desde o Nordeste do Brasil”. In: VI Congresso Chileno de Antropologia, 2007.

MOTTA, Roberto; SCOTT, Parry. Sobrevivência e fontes de renda: estratégias das famílias de baixa renda no Recife. Recife: Ed. Massangana, 1983.

RAMALHO, José Ricardo; SANTANA, Aurélio. Trabalhadores, sindicatos, e a nova questão social. In: RAMALHO, J. R.; SANTANA, A. Além da fábrica: trabalhadores, sindicatos e a nova questão social. São Paulo: Boitempo, 2003, p.11-43.

RIBEIRO, Gustavo Lins. “A condição da transnacionalidade”. In: Série Antropologia. ISSN 1980-9867. Vol. 223, Brasília: DAN/UnB, 1997.

2006, pp.233-249. . "Economic globalization from below". Etnográfica, Vol X (2), nov., "El sistema mundial no-hegemónico y la globalizactión popular". In: Série Antropologia. ISSN 1980-9867. Vol. 410, Brasília: DAN/UnB, 2007.

RODRIGUES, Ivanildo Dias. "Os camelôs e as atividades conexas que compõem o circuito de circulação das mercadorias". In: Revista Pegada. Vol.08. N.01. Junho de 2007. pp.129152.

SAHLINS, Marshall. Cultura na prática. Rio de Janeiro: UFRJ, 2004.

. O "pessimismo sentimental e a experiência etnográfica: por que a cultura não é um objeto em via de extensão" (Parte I). In: Mana. Rio de Janeiro, v.03, n.01, 1997.

SANTOS, Milton. "Lazer popular e geração de empregos". In: Lazer numa sociedade globalizada. São Paulo: SESC /WRLA, 2000, p. 31-37.

TURNER,Victor. O processo ritual: estrutura e antiestrutura. Petrópolis, RJ: Editora Vozes, 1974.

URRY, John. $O$ olhar do turista: lazer e viagens nas sociedades contemporâneas. $3^{\text {a }}$ ed. São Paulo: Studio Nobel: SESC, 2001. 